\title{
Marek Jansen
}

\section{Der Nachrichtenmarkt in der Industriellen Revolution}

Zur Entwicklung und rechtlichen Gestaltung des Nachrichtenmarktes im Kontext von Wolff's Telegraphischem Bureau (1849-1914)

[The News Market during the Industrial Revolution. On the Development and Legal Formation of the News Market Based on the Wolff Telegraphic Bureau (1849-1914).]

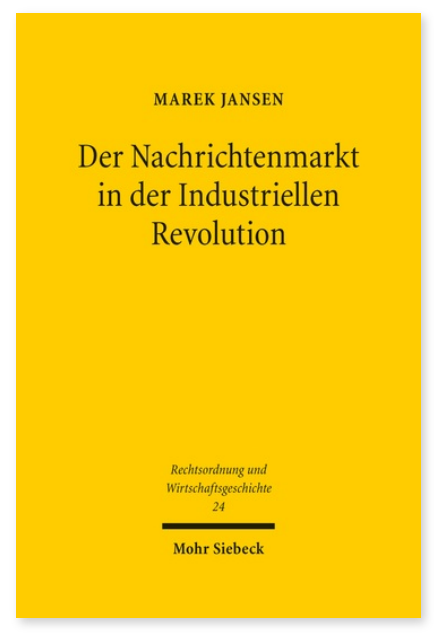

2022. XVII, 234 pages. ROWG 24

ISBN 978-3-16-159353-6

cloth $84,00 €$

ISBN 978-3-16-159354-3

eBook PDF $84,00 €$
Published in German.

Marek Jansen examines how the news market developed and the legal form it took on during the Industrial Revolution from the mid-nineteenth century. Taking the Wolff Telegraphic Bureau as an example, he reveals the interactions between the company and the legal system as well as showing how the relationship between political, economic, and technological changes influenced the market's development.

Marek Jansen Geboren 1984; Studium der Rechtswissenschaft an der Universität Bonn; Mitarbeiter am Institut für Deutsche und Rheinische Rechtsgeschichte der Universität Bonn; Erstes Juristisches Staatsexamen am OLG Köln; Wissenschaftlicher Mitarbeiter im Deutschen Bundestag; Zweites Juristisches Staatsexamen am KG Berlin; Co-Gründer und Geschäftsführer der Digitalberatungsagentur Perdoctum; Rechtsanwalt in Berlin und Syndikusrechtsanwalt beim Bundesverband der Deutschen Industrie Berlin; derzeit Data Governance Manager, Public Policy and Government Relations bei Google.
Order now:

https://www.mohrsiebeck.com/en/book/der-nachrichtenmarkt-in-der-industriellen-revolution-9783161593536?no_cache=1 order@mohrsiebeck.com

Phone: +49 (0)7071-923-17

Fax: +49 (0)7071-51104 